\title{
Founder Mutations for Early Onset Melanoma as Revealed by Whole Exome Sequencing Suggests That This is Not Associated with the Increasing Incidence of Melanoma in Poland
}

\author{
Tadeusz Dębniak, MD ${ }^{1}$ \\ Rodney J Scott, MD2 \\ Rodney A Lea, $\mathrm{PhD}^{3}$ \\ Bohdan Górski, MD, PhD' \\ Bartłomiej Masojć, MD, $\mathrm{PhD}^{4}$ \\ Cezary Cybulski, MD \\ Andrzej Kram, MD, PhD ${ }^{4}$ \\ Romuald Maleszka, MD ${ }^{5}$ \\ Tomasz Gromowski, PhD \\ Katarzyna Paszkowska-Szczur, PhD' \\ Aniruddh Kashyap, MD, PhD ${ }^{1}$ \\ Marcin R. Lener, $\mathrm{PhD}^{1}$ \\ Karolina Malińska, MSC ${ }^{1}$ \\ Emilia Rogoża, MSc ${ }^{1}$ \\ Dawid Murawa, MD, $\mathrm{PhD}^{6}$ \\ Helena Rudnicka, $\mathrm{PhD}^{1}$ \\ Jakub Deptuła, MSc \\ Jan Lubiński, MD'
}

*A list author's affiliations appears at the end of the paper.

\begin{abstract}
Purpose
Germline mutations within melanoma susceptibility genes are present only in minority of melanoma patients and it is expected that additional genes will be discovered with next generation sequence technology and whole-exome sequencing (WES).
\end{abstract}

\section{Materials and Methods}

Herein we performed WES on a cohort of 96 unrelated Polish patients with melanoma diagnosed under the age of 40 years who all screened negative for the presence of CDKN2Avariants. A replication study using a set of 1,200 melanoma patient DNA samples and similarly large series of healthy controls was undertaken.

Results

We selected 21 potentially deleterious variants in 20 genes (VRK1, MYCT1, DNAH14, CASC3, MS4A12, PRC1, WWOX, CARD6, EX05, CASC3, CASP8AP2, STK33, SAMD11, CNDP2, CPNE1, EFCAB6, CABLES1, LEKR1, NUDT17, and RRP15), which were identified by WES and confirmed by Sanger sequencing for an association study. Evaluation of the allele distribution among carriers and their relatives in available family trios revealed that these variants were unlikely to account for many familial cases of melanoma. Replication study revealed no statistically significant differences between cases and controls.

\section{Conclusion}

Although most of the changes seemed to be neutral we could not exclude an association between variants in VRK1, CREB3L3, EXO5, and STK33 with melanoma risk.

Key words

Whole exome sequencing, Melanoma, Frameshift mutation
Correspondence: Tadeusz Dębniak, MD Department of Genetics and Pathology, International Hereditary Cancer Center, Pomeranian Medical University,

Unia Lubelska 1, 71-252 Szczecin, Poland

Tel: 48-91-441-7250

Fax: 48-91-441-7251

E-mail: debniak@pum.edu.pl

Received March 14, 2018

Accepted May 8, 2018

Published Online May 14, 2018 


\section{Introduction}

Melanoma is one of the most aggressive human malignancies. The mean survival time for metastatic patients is 6 months when standard chemotherapy is used or up to 12 months if used in combination with the BRAF enzyme inhibitor vemurafenib. The incidence of melanoma has been increasing dramatically in the Caucasian population since the 1950s [1].

In Poland the number of affected individuals has increased by $60 \%$ over the past 11 years and has reached over 2,600 new cases identified annually. The etiology of melanoma is complex, involving both genetic and environmental factors. Significant heritability of this malignancy was observed in large twin study [2].

Family studies provide strong support for heterogeneous mechanisms involved in a polygenic inherited susceptibility to melanoma that includes both inherited high-risk and lowrisk alleles. To date only one major melanoma susceptibility gene: $C D K N 2 A$ has been identified, responsible for only up to $20 \%$ of melanoma-prone patients [3]. Mutations within other malignant melanoma (MM) high-risk genes, such as CDK4, ACD, CXC, TERT, TERF2IP, BAP1, or POT1 are extremely rare and to date have been identified only in few families worldwide. Because germline mutations in CDKN2A are present in a minority of melanoma patients it is expected that additional genes will be discovered with next generation sequence technology that focuses on whole-exome or wholegenome sequencing. Onset of MM at an early age is suggestive of a hereditary predisposition. However, the heritability of early-onset MM remains unexplained even in a larger proportion of apparent sporadic cases than among familial cases. Thus far in the literature there appears to be a paucity of data from whole exome sequencing among early-onset MM cases.

Given the unique homogenous structure of the Polish population, we undertook an exome screen to determine if there existed one or more novel high/moderate risk gene(s) for MM, which may be associated with specific founder effects. Herein, we performed whole-exome sequencing (WES) on a cohort of 96 unrelated Polish patients with melanoma diagnosed under the age of 40 years. All of whom had previously been screened for the present of causative CDKN2A-variants and found not to harbor any. We studied both recessive and dominant inheritance patterns by analyses of both sporadic and familial early onset MM cases. We evaluated protein truncating DNA alterations only and selected genes for further study based on the relevance of the gene to carcinogenesis.

In the subsequent verification step, we evaluated recurrent truncating mutations identified by WES in large case-control study of 1,200 unselected MM patients and 6,200 control sub- jects from Poland.

\section{Materials and Methods}

\section{Study subjects}

\section{1) Discovery phase}

In the first step of this study, we have performed whole exome sequencing in a cohort of 96 unrelated patients with early-onset ( $<40$ years) melanoma who all screened negative for CDKN2A-causative variants (65 females; mean age, 30.8 years; range, 15 to 40 years and 31 males; mean age, 30.9 years; range, 18 to 39 years). Half of the patients (48 cases) were also characterized by a familial aggregation of melanoma among first- or second-degree relatives.

\section{2) Validation phase}

We verified the role of variants revealed by WES using a large case control-study of 1,230 unselected melanoma patients (760 females; mean age, 53.9 years; range, 15 to 92 years and 470 males; mean age, 55 years; range, 18 to 84 years) from Poland. 748 unselected MM cases (464 women; mean age, 53.7 years; 284 men) comprising $62.3 \%$ of the total group were diagnosed between 2002 and 2006 and identified from cancer registries in five Polish cities (Szczecin, Opole, Bialystok, Zielona Gora, and Gorzow Wielkopolski). The registries capture more than $95 \%$ of all diagnosed melanomas. The remaining $482(37.7 \%$ ) unselected MM cases (296 females, 186 males) were diagnosed in the city of Szczecin between the years 2010 and 2016.

The control group consisted two non-overlapping cohorts of healthy adults. All mutations that were confirmed by Sanger sequencing were genotyped in a group of 1,696 healthy adults (943 women, 753 men) with no cancers diagnosed in their families. The healthy adults were assessed as having a negative cancer family history (first- and seconddegree relatives included) after answering questionnaires about their family's medical history, which was part of a population-based study of the 1.5 million residents of West Pomerania aimed at identifying familial aggregations of malignancies performed recently by our center. During the interview, the goals of the study were explained, informed consent was obtained, genetic counseling was given and a blood sample was taken for DNA analysis. Individuals affected with any malignancy or with cancers diagnosed among first- or second-degree relatives were excluded from our study control group. 
Variants with significantly different allele distribution among cases and the first cohort of controls, described above, were additionally genotyped in a second cohort of 5,000 healthy adults (1,775 men; mean age, 58 years and 3,225 females; mean age, 60 years) who underwent genetic counselling and were diagnosed as having no genetically increased risk of cancer on the basis of molecular examination and a negative cancer family history. During the interview, the goals of the study were explained, informed consent was obtained, genetic counseling was given and a blood sample was taken for DNA analysis. Individuals affected with any malignancy or with cancers diagnosed among firstor second-degree relatives were excluded from our study control group.

Overall, patient participation rates exceeded $75 \%$. All patients and control subjects were of European ancestry and ethnic Poles.

\section{Whole exome sequencing}

DNA has been isolated using standard methods from peripheral blood leukocytes taken from participants in Department of Genetics and Pathology in Szczecin.

The Illumina Nexter Rapid Capture Expanded Exome kit (target region size $=62 \mathrm{MB}$, coding exons, untranslated regions (UTRs) and miRNAs included; Illumina, San Diego, CA) was used for capturing sequence target regions. The kit captured $62 \mathrm{Mbp}$ of the human genome covering coding exons in CCDS and RefSeq databases as well as exons annotated by GENCODE project. The captured regions for each sample were barcoded and every two samples were pooled and used for paired-end sequencing for 100 cycles (generating $100 \mathrm{bp}$ reads) on a single lane of Illumina HiSeq2000's flow-cell. The 100 million reads for each exome sequence for each individual were aligned to the reference sequence of the human genome using Burrows-Wheeler transform algorithm [4]. SAMtools [5] and GATK [6] packages as well as SCALPEL algorithm [7] were used for calling variants.

We considered only those genes with a minimum of two patients as candidates for further studies.

We employed disease-network approach to select those genes which are functionally more related to cancer pathogenesis (such as DNA repair and cell cycle control pathway genes) using the ToppGene algorithm [8].

\section{Sanger sequencing}

Each variant identified by WES in the discovery phase and selected for validation was confirmed by Sanger direct sequencing. Sequencing reactions were performed using the BigDye Terminator v3.1 Cycle Sequencing kit (Life Technologies, Foster City, CA). according to the manufacturer's pro- tocol. Sequencing products were analyzed on the ABI Prism 3500XL Genetic Analyzer (Life Technologies). All sequences were compared reference sequences for variant detection using Mutation Surveyor software (SoftGenetics).

\section{TaqMan genotyping}

DNA was isolated from 5 to $10 \mathrm{~mL}$ of peripheral blood. The validated variants were genotyped using a TaqMan assay (Applied Biosystems/Life Technologies) and the LightCycler Real-Time PCR 480 system (Roche Life Science, Indianapolis, IN). The primer and probe sequences are available upon request. Laboratory technicians were blinded to casecontrol status. The overall genotyping call rate was $99.3 \%$. The presence of the mutation was confirmed by Sanger sequencing as described above.

\section{Data analysis}

All genotype comparisons between cases and controls were performed using Fisher exact test, and two-tailed p-values were calculated. OR values were calculated for each comparison together with their $95 \%$ confidence intervals. To exclude recessive trait of inheritance we performed additional genotyping of parents and siblings of patients with identified mutations from the cohort of 96 early-onset MM cases.

\section{Ethical statement}

The Polish study was approved by the ethics committee of Pomeranian Medical University (Szczecin, Poland). All study subjects provided a signed consent form for participation in the study.

\section{Results}

Using GATK algorithm, we detected 2,272,282 indels in the total data set for our cohort of early-onset melanoma patients, after prioritization we identified 1,012 new and 218 previously reported frameshift mutations (523 new variants in sporadic early-onset cases and 489 in familial cases; 137 previously reported variants in sporadic cases and 81 in familial cases). Using SCALPEL algorithm, we detected 2,297 variants (1,151 of them in sporadic early-onset cases, 1,146 in familial cases). These comprised $3^{\prime}$ UTR and $5^{\prime}$ UTR variants (452 and 56, respectively), 228 downstream variants, 88 in frame deletions, 40 intergenic variants, 1,000 intron variants, 11 intron variants and NMD transcript variants, 55 intron 
Table 1. Allele distribution among carriers and their relatives in trios-available families

\begin{tabular}{|c|c|c|c|c|c|c|c|}
\hline Gene (mutation) & Position & Proband & Father & Mother & Brother & 2nd brother & Sister \\
\hline \multirow[t]{2}{*}{ VRK1 (delTG) } & 96860761 & het mut ${ }^{\mathrm{a})}$ & $0^{\mathrm{b})}$ & het mut & 0 & 0 & 0 \\
\hline & & het mut & het mut & hom $w t^{c)}$ & 0 & 0 & 0 \\
\hline \multirow[t]{3}{*}{ MYCT1 (delAGAT) } & 152697964 & het mut & het mut & hom wt & 0 & 0 & 0 \\
\hline & & het mut & 0 & het mut & 0 & 0 & 0 \\
\hline & & het mut & het mut & hom wt & 0 & 0 & 0 \\
\hline \multirow{2}{*}{ DNAH4 (delAAGA) } & 225192859 & het mut & hom wt & het mut & het mut & het mut & 0 \\
\hline & & hom mut ${ }^{\text {d) }}$ & hom mut & hom mut & 0 & 0 & 0 \\
\hline CASC3 (delT) & 40141200 & het mut & het mut & hom wt & 0 & 0 & 0 \\
\hline MS4A12 (delA) & 60497504 & het mut & het mut & hom wt & hom wt & 0 & 0 \\
\hline \multirow[t]{2}{*}{ PRC1 (delCACA) } & 90966617 & het mut & het mut & hom wt & 0 & 0 & 0 \\
\hline & & het mut & het mut & hom wt & 0 & 0 & 0 \\
\hline \multirow[t]{2}{*}{ WWOX (insAAGTA) } & 79211976 & het mut & hom wt & hom mut & 0 & 0 & 0 \\
\hline & & het mut & hom wt & het mut & 0 & 0 & 0 \\
\hline \multirow[t]{2}{*}{ WWOX (delGGGCT ) } & 7921995 & het mut & hom wt & het mut & 0 & 0 & 0 \\
\hline & & het mut & het mut & hom wt & 0 & 0 & 0 \\
\hline \multirow[t]{2}{*}{ CARD6 (delTT) } & 40841469 & het mut & het mut & hom wt & 0 & 0 & 0 \\
\hline & & het mut & hom wt & het mut & 0 & 0 & 0 \\
\hline \multirow[t]{2}{*}{ EFCAB6 (delCT) } & 43537404 & het mut & het mut & hom wt & 0 & 0 & 0 \\
\hline & & het mut & het mut & 0 & 0 & 0 & hom wt \\
\hline EXO5 (delG) & 40515573 & het mut & het mut & hom wt & 0 & 0 & 0 \\
\hline STK33 (insAACCA) & 8392543 & het mut & het mut & hom wt & 0 & 0 & 0 \\
\hline \multirow[t]{4}{*}{ SAMD11 (insT) } & 939436 & hom mut & het mut & hom mut & 0 & 0 & 0 \\
\hline & & hom mut & het mut & hom mut & 0 & 0 & 0 \\
\hline & & hom mut & het mut & hom mut & 0 & 0 & 0 \\
\hline & & hom mut & hom mut & het mut & 0 & 0 & 0 \\
\hline \multirow[t]{5}{*}{ CPNE1 (delA) } & 35627312 & het mut & hom mut & hom wt & 0 & 0 & 0 \\
\hline & & het mut & hom mut & hom wt & 0 & 0 & 0 \\
\hline & & het mut & 0 & hom wt & het mut & 0 & 0 \\
\hline & & het mut & 0 & het mut & 0 & 0 & 0 \\
\hline & & het mut & 0 & 0 & 0 & 0 & het mut \\
\hline \multirow[t]{4}{*}{ CABLES1 (delCG) } & 23136057 & het mut & het mut & hom mut & 0 & 0 & 0 \\
\hline & & het mut & hom mut & 0 & het mut & het mut & 0 \\
\hline & & het mut & hom mut & het mut & 0 & 0 & 0 \\
\hline & & het mut & hom wt & het mut & 0 & 0 & 0 \\
\hline \multirow[t]{4}{*}{ LEKR1 (delT) } & 156979266 & het mut & hom wt & het mut & 0 & 0 & 0 \\
\hline & & het mut & het mut & hom wt & 0 & 0 & 0 \\
\hline & & het mut & hom wt & hom mut & 0 & 0 & 0 \\
\hline & & het mut & 0 & hom wt & het mut & 0 & 0 \\
\hline \multirow[t]{2}{*}{ NUDT17 (delG) } & 145847527 & het mut & hom wt & hom mut & 0 & 0 & 0 \\
\hline & & hom mut & het mut & hom mut & 0 & 0 & 0 \\
\hline RRP 15 (delC) & 218331057 & het mut & hom wt & hom mut & 0 & 0 & 0 \\
\hline CASP8AP2 (delG) & 89867987 & hom mut & hom mut & het mut & 0 & 0 & het mut \\
\hline
\end{tabular}

${ }^{a}$ a) Heterozygous mutation, ${ }^{\mathrm{b}}$ Not examined, ${ }^{\mathrm{c}}$ Homozygous wild type, ${ }^{\mathrm{d}}$ Homozygous mutation. In all cases parents and siblings were not diagnosed with melanoma.

variants and non-coding transcript variants, 57 non-coding transcript exon variants and noncoding transcript variants, five regulatory regions variants, three splice acceptor variants, 60 splice region variants and intron variants, two tran- scription factor variants, one splice region variant and intron variant and noncoding transcript variant, 161 upstream gene variants and 74 frameshift mutations.

The frameshift mutations were selected for further inter- 
Table 2. Prevalence of the validated potentially protein-truncating variants among cases and controls

\begin{tabular}{|c|c|c|c|c|c|c|}
\hline \multirow{2}{*}{ Gene/mutation } & \multirow{2}{*}{$\operatorname{POS}^{\mathrm{a})}$} & \multirow{2}{*}{ Genotype } & \multicolumn{2}{|c|}{ No. $(\%)$} & \multirow{2}{*}{$\begin{array}{l}\text { Odds } \\
\text { ratio }\end{array}$} & \multirow{2}{*}{$\begin{array}{l}\text { Significance } \\
\text { level p-value }\end{array}$} \\
\hline & & & MM & CONTROLS & & \\
\hline \multirow[t]{3}{*}{ WWOX (insAAGTA) } & 79211976 & ALLELE $X^{\mathrm{b})}$ & 1,058 (91.0) & 1,399 (90.4) & & \\
\hline & & Heterozygote XY & $102(8.8)$ & $143(9.2)$ & 0.943 & 0.667 \\
\hline & & ALLELE $Y^{(c)}$ & $4(0.3)$ & $5(0.3)$ & 1.058 & 0.933 \\
\hline \multirow[t]{3}{*}{ WWOX (delGGGCT) } & 7921995 & ALLELE X & $1,160(97.8)$ & $1,603(98.5)$ & & \\
\hline & & Heterozygote XY & $23(1.9)$ & $23(1.4)$ & 1.382 & 0.277 \\
\hline & & ALLELE Y & $3(0.3)$ & $2(0.1)$ & 2.073 & 0.425 \\
\hline \multirow[t]{3}{*}{ VRK1 (delTG) } & 96860761 & ALLELE X & $789(89.2)$ & $761(86.4)$ & & \\
\hline & & Heterozygote XY & $96(10.8)$ & $114(12.9)$ & 0.945 & 0.698 \\
\hline & & ALLELE Y & 0 & $6(0.7)$ & 0.086 & 0.095 \\
\hline \multirow[t]{3}{*}{ NUDT17 (delG) } & 145847527 & ALLELE X & $1,008(95.0)$ & $1,720(94.1)$ & & \\
\hline & & Heterozygote XY & $47(4.4)$ & $104(5.7)$ & 0.771 & 0.149 \\
\hline & & ALLELE Y & $2(0.2)$ & $3(0.2)$ & 1.138 & 0.888 \\
\hline \multirow[t]{3}{*}{ SAMD11 (insT) } & 939436 & ALLELE Y & $101(9.0)$ & $194(11.9)$ & & \\
\hline & & Heterozygote XY & $1,003(90.2)$ & $1,415(86.9)$ & 0.594 & 0.219 \\
\hline & & ALLELE X & $8(0.7)$ & $19(1.2)$ & 0.809 & 0.629 \\
\hline \multirow[t]{3}{*}{ DNAH14 (delAAGA) } & 225192859 & ALLELE X & $919(87.0)$ & 1,561 (87.1) & & \\
\hline & & Heterozygote XY & $134(12.6)$ & $221(12.3)$ & 1.030 & 0.801 \\
\hline & & ALLELE Y & $7(0.7)$ & $10(0.6)$ & 1.189 & 0.726 \\
\hline \multirow[t]{3}{*}{ CABLES1 (delCG) } & 23136057 & ALLELE X & $805(88.0)$ & $1,447(87.1)$ & & \\
\hline & & Heterozygote XY & 107 (11.7) & $204(12.3)$ & 0.943 & 0.643 \\
\hline & & ALLELE Y & $5(0.5)$ & $11(0.6)$ & 0.817 & 0.709 \\
\hline \multirow[t]{2}{*}{ CREB3L3 (insG) } & 4168367 & ALLELE X & $1,210(99.0)$ & $1,501(99.5)$ & & \\
\hline & & Heterozygote XY & $12(1.0)$ & $7(0.5)$ & 2.127 & 0.114 \\
\hline \multirow[t]{3}{*}{ EFCAB6 (delCT) } & 43537404 & ALLELE X & $1,110(93.7)$ & $907(93.1)$ & & \\
\hline & & Heterozygote XY & $74(6.2)$ & $63(6.5)$ & 0.960 & 0.817 \\
\hline & & ALLELE Y & $1(0.1)$ & $4(0.4)$ & 0.204 & 0.156 \\
\hline \multirow[t]{3}{*}{ MYCT1 (delAGAT) } & 152697964 & ALLELE X & $1,135(94.9)$ & $3,874(94.9)$ & & \\
\hline & & Heterozygote XY & $59(4.9)$ & $200(4.9)$ & 1.007 & 0.964 \\
\hline & & ALLELE Y & $2(0.2)$ & $6(0.1)$ & 1.138 & 0.874 \\
\hline \multirow[t]{3}{*}{ CARD6 (delTT) } & 40841469 & ALLELE X & 1,144 (95.9) & $1,631(96.2)$ & & \\
\hline & & Heterozygote XY & $48(4.0)$ & $65(3.8)$ & 1.053 & 0.791 \\
\hline & & ALLELE Y & $1(0.1)$ & 0 & 4.276 & 0.374 \\
\hline \multirow[t]{3}{*}{ CPNE1 (delA) } & 35627312 & ALLELE X & $943(79.4)$ & $834(79.5)$ & & \\
\hline & & Heterozygote XY & $229(19.3)$ & $204(19.4)$ & 0.993 & 0.946 \\
\hline & & ALLELE Y & $15(1.3)$ & $11(1.1)$ & 1.206 & 0.639 \\
\hline \multirow[t]{3}{*}{ EXO5 (delG) } & 40515573 & ALLELE X & $1,142(97.2)$ & $1,640(96.4)$ & & \\
\hline & & Heterozygote XY & $32(2.7)$ & $54(3.2)$ & 0.851 & 0.476 \\
\hline & & ALLELE Y & $1(0.1)$ & $7(0.4)$ & 0.205 & 0.139 \\
\hline \multirow[t]{2}{*}{ RRP15 (delC) } & 218331057 & ALLELE X & $1,126(98.6)$ & $1,020(98.1)$ & & \\
\hline & & Heterozygote XY & $16(1.4)$ & $20(1.9)$ & 0.811 & 0.536 \\
\hline MS4A12 (delA) & 60497504 & ALLELE X & $1,159(96.3)$ & $6,216(97.3)$ & & \\
\hline & & Heterozygote XY & $45(3.7)$ & $175(2.7)$ & 1.379 & 0.059 \\
\hline & & ALLELE Y & 0 & $1(0.03)$ & 1.787 & 0.722 \\
\hline PRC1 (delCACA) & 90966617 & ALLELE X & $1,053(95.2)$ & $4,595(94.8)$ & & \\
\hline & & Heterozygote XY & $49(4.4)$ & $233(4.8)$ & 0.918 & 0.593 \\
\hline & & ALLELE Y & $4(0.4)$ & $18(0.4)$ & 0.970 & 0.956 \\
\hline CASC3 (delT) & 40141200 & ALLELE X & $1,132(93.0)$ & $6,137(93.1)$ & & \\
\hline & & Heterozygote XY & $82(6.7)$ & $445(6.7)$ & 0.999 & 0.994 \\
\hline & & ALLELE Y & $3(0.3)$ & $13(0.2)$ & 1.251 & 0.727 \\
\hline
\end{tabular}

(Continued to the next page) 
Table 2. Continued

\begin{tabular}{|c|c|c|c|c|c|c|}
\hline \multirow{2}{*}{ Gene/mutation } & \multirow{2}{*}{$\operatorname{POS}^{\mathrm{a})}$} & \multirow{2}{*}{ Genotype } & \multicolumn{2}{|c|}{ No. $(\%)$} & \multirow{2}{*}{$\begin{array}{l}\text { Odds } \\
\text { ratio }\end{array}$} & \multirow{2}{*}{$\begin{array}{l}\text { Significance } \\
\text { level p-value }\end{array}$} \\
\hline & & & MM & CONTROLS & & \\
\hline \multirow[t]{2}{*}{ LEKR1 (delT) } & 156979266 & ALLELE X & $1,144(95.6)$ & $1,018(95.0)$ & & \\
\hline & & Heterozygote XY & $53(4.4)$ & $53(5.0)$ & 0.890 & 0.558 \\
\hline \multirow[t]{2}{*}{ CNDP2 (delTT) } & 74520191 & ALLELE X & 1,207 (99.0) & 1,774 (99.0) & & \\
\hline & & Heterozygote XY & $12(1.0)$ & $18(1.0)$ & 0.980 & 0.957 \\
\hline \multirow[t]{3}{*}{ STK33 (insAACCA) } & 8392543 & ALLELE X & $1,084(95.0)$ & $4,658(96.0)$ & & \\
\hline & & Heterozygote XY & $59(5.2)$ & $191(3.9)$ & 1.327 & 0.064 \\
\hline & & ALLELE Y & $1(0.1)$ & $2(0.04)$ & 2.148 & 0.532 \\
\hline \multirow[t]{3}{*}{ CASP8AP2 (delG) } & 89867987 & ALLELE X & $703(76.4)$ & $843(77.4)$ & & \\
\hline & & Heterozygote XY & $186(20.2)$ & $200(18.4)$ & 0.897 & 0.337 \\
\hline & & ALLELE Y & $31(3.4)$ & $46(4.2)$ & 0.725 & 0.213 \\
\hline
\end{tabular}

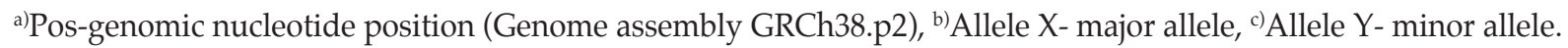

rogation as they were most likely to reveal new genes of interest with respect to melanoma development.

All the frameshift mutations were filtered by examining the quality control values, minor allele frequencies and intense gene databases / literature data analysis supported by the ToppGene algorithm. We selected 21 potentially deleterious variants in 20 genes, which after confirmation by Sanger sequencing were evaluated in the association study. These included the genes VRK1 (a serine/threonine kinase actively expressed in dividing cells), MYCT1 (proposed to regulate certain MYC target genes), DNAH14 (involved in microtubule motilities), CASC3 (functions in nonsense mediated mRNA decay), MS4A12 (associated with inhibition of cellular proliferation of colon cancer cells), PRC1 (a key regulator of cytokinesis), WWOX (acts as a tumour supressor, expression is associated with apoptosis), CARD6 (encodes a caspase recruitment domain that may be involved in apoptosis), EFCAB6 (encodes a protein which directly binds the oncogene DJ-1 and androgen receptor), EXO5 (involved in DNA repair following Uv-light irradiation), CASC3 (known as cancer susceptibility 3 and involved in nonsensemediated mRNA decay), STK33 (a serine threonine kinase involved in MAP kinase signaling), SAMD11 (transcription coactivator activity and $\mathrm{PH}$ domain binding required to maintain the transcriptionally repressive state of many genes), CPNE1 (involved in calcium mediated intra-cellular processes), CABLES1 (a cyclin dependent kinase binding protein that is involved in p53/p73 induced cell death), LEKR1 (structural constituent of ribosome), NUDT17 (most likely mediates the hydrolysis of some nucleoside disphosphate derivatives), CASP8AP2 (plays a regulatory role in Fasmediated apoptosis), RRP 15 (a ribosomal protein subunit), and CREB3L3 (member of the basic-leucine zipper family and the AMP-dependent transcription factor family, linked to acute inflammatory response and hepatocellular carcinoma). Mutations in VRK1, MYCT1, DNAH14, MS4A12, PRC1, CARD6, STK33, EFCAB6, EXO5, and SAMD11 genes were found among early onset cases; CREB3L3, CNDP2, CABLES1, RRP 15, and CASP8AP2 genes in familial cases; CASC3, WWOX, CPNE1, LEKR1, and NUDT17 in both subgroups.

The variants in these genes were further investigated in those families where trios were available to determine if they were recessively or dominantly inherited. The results of this aspect of the study revealed that there were some genetic variants that were homozygous in the proband and in one or other of the parents. Further evaluation revealed that these variants were unlikely to be associated with disease since either the unaffected parents were both homozygous for the allele and the proband heterozygous or the proband was homozygous for the variant and one of the parents were homozygous and the other heterozygous for that specific allele. Genotyping of the parents of homozygous carriers of identified mutations revealed no case of homozygous proband and both parents being the carriers of the mutations. Together, this suggested that those variants were unlikely to be associated with any change in melanoma risk (Table 1).

Additional evidence about the pathogenicity of the identified variants was provided by a replication study where a set of 1,200 melanoma patient DNA samples was compared to a similarly large series of control DNA samples taken from healthy subjects (Table 2).

The results revealed that most of the changes were neutral but although we found no statistically significant differences between cases and controls, 10 genes cannot be excluded as being associated with melanoma risk-due to genetic heterogeneity and the reduced penetrance of this disease. A greater level of confidence in the pathogenicity of the variant was 
observed if the homozygous state was associated with a greater difference in risk compared to being in the heterozygote state. Unfortunately, many of the variants occurred within the study populations at much lower frequency to be reliably associated with disease risk. Potential candidates included WWOX, VRK1, CREB3L3, EFCAB6, CARD6, EXO5, $M S 4 A 12, C A S C 3$, and STK3. From this list of genes, the most promising were VRK1, CREB3L3, EXO5, and STK33 as there was a tendency of decreasing risk of melanoma for heterozygote and homozygote carriers of VRK1 and EXO5 and an increasing risk of disease for CREB3L3 and STK33.

\section{Discussion}

From 2008 to 2013, the approach of finding melanoma susceptibility genes centered on genome-wide association studies (GWAS). The results of several of these studies aimed at identifying susceptibility loci for melanoma have been reported [9-12]. The results of these studies have reported new susceptibility loci for melanoma, but the effect sizes reported from these GWAS have been modest with odds ratios at best being $\sim 1.5$. None of the GWAS has thus far led to the adoption of a clinical test for a newly discovered genetic locus.

Low-penetrance variants cannot be categorically associated with familial clusters, for many reasons that include molecular interactions between low/moderate penetrance genes, which could potentially be responsible for early-onset disease.

Recently, WES has been developed which overcomes many of the problems of GWAS [6]. It is estimated that the protein coding regions of the human genome (exons) constitute about $85 \%$ of disease-causing mutations [13]. Wholeexome and whole-genome studies have identified numerous genes somatically altered in melanoma tumors and highlighted a higher mutation load in melanoma compared with those in other cancers, such as, TP53, NF1, and ARID2 $[14,15]$. However, to date only a few new genes / cancer susceptibility alleles in melanoma-prone families have been identified using whole exome or whole genome sequencing. Germline mutations of all of the genes identified to date are found in a very small proportion of families that can not account for the growing frequency of the disease. The list includes the TERT promoter mutation found among German familial melanoma patients [16], a POLE1 missense mutation detected in one family [17], $A C D$ with mutations in six families and four families carrying TERF2IP variants, which included nonsense mutations in both genes) and point mutations that co-segregated with melanoma [18]; finally a
$R A D 51 B$ nonsense mutation was identified in one family [19]. WES also identified a BAP1 splice mutation occurring in a family with uveal MM [20]. Direct Sanger sequencing of this gene revealed germline mutation among early-onset uveal patients [21].

Given the homogeneity of the Polish population we expected to find a limited number of recurrent founder mutations. However, we found large numbers of germline DNA alterations which appeared causative as they were predicted to result in truncated protein products, but none appeared to be novel high-risk melanoma gene in either sporadic familial early-onset patients. We observed known recurrent truncating mutations in genes predisposing to other cancers, such as NOD2 (3020insC), CHEK2 (1100delC, IVS2+1G>A, del5395), and NBS1 (657del5). Their distribution among melanoma patients was not significantly different to that observed amongst healthy controls (data available upon request). Although evaluation of somatic mutations was not the subject of the study, it would be very interesting to compare the results from melanoma skin and blood samples. Increased frequency of somatic mutations could point at melanoma-susceptibility candidate genes.

Taken together the results from this study with respect to the Polish population suggests that there is extensive genetic heterogeneity within melanoma families from Poland that can not be explained by a few recurrent highly penetrant causal variants. Large multi-center studies are needed for further investigation of possible involvement of VRK1, CREB3L3, EXO5, and STK33 genes in melanoma development. Additionally to reveal the genetic association with new mutation with relation with early-onset melanoma long, prospective follow-up study of the families with identified DNA variants is needed.

\section{Conflicts of Interest}

Conflict of interest relevant to this article was not reported.

\section{Acknowledgments}

This study was supported by the Polish National Science Centre (grant number 2014/13/B/NZ2/03888). 


\section{Author Details}

${ }^{1}$ Department of Genetics and Pathomorphology, International Hereditary Cancer Center, Pomeranian Medical University in Szczecin, Szczecin, Poland, ${ }^{2}$ School of Biomedical Sciences and Pharmacy, Faculty of Health, University of Newcastle and the Hunter Medical
Research Institute, Newcastle, ${ }^{3} \mathrm{MS}$ Research Group, Hunter Medical Research Institute, University of Newcastle, New Lambton, Australia, ${ }^{4}$ West Pomeranian Oncology Center, Szczecin, ${ }^{5}$ Department of Skin Diseases and Venerology PUM, Siedlecka, Police, ${ }^{6}$ Department of Oncological and General Surgery, Greater Poland Cancer Center, Garbary Poznań, Poland

\section{References}

1. Ferlay J, Steliarova-Foucher E, Lortet-Tieulent J, Rosso S, Coebergh JW, Comber H, et al. Cancer incidence and mortality patterns in Europe: estimates for 40 countries in 2012. Eur J Cancer. 2013;49:1374-403.

2. Mucci LA, Hjelmborg JB, Harris JR, Czene K, Havelick DJ, Scheike T, et al. Familial risk and heritability of cancer among twins in Nordic countries. JAMA. 2016;315:68-76.

3. Goldstein AM, Chan M, Harland M, Hayward NK, Demenais F, Bishop DT, et al. Features associated with germline CDKN2A mutations: a GenoMEL study of melanoma-prone families from three continents. J Med Genet. 2007;44:99-106.

4. Li H, Durbin R. Fast and accurate short read alignment with Burrows-Wheeler transform. Bioinformatics. 2009;25:1754-60.

5. Li H, Handsaker B, Wysoker A, Fennell T, Ruan J, Homer N, et al. The Sequence Alignment/Map format and SAMtools. Bioinformatics. 2009;25:2078-9.

6. McKenna A, Hanna M, Banks E, Sivachenko A, Cibulskis K, Kernytsky A, et al. The Genome Analysis Toolkit: a MapReduce framework for analyzing next-generation DNA sequencing data. Genome Res. 2010;20:1297-303.

7. Narzisi G, O'Rawe JA, Iossifov I, Fang H, Lee YH, Wang Z, et al. Accurate de novo and transmitted indel detection in exome-capture data using microassembly. Nat Methods. 2014;11:1033-6.

8. Chen J, Xu H, Aronow BJ, Jegga AG. Improved human disease candidate gene prioritization using mouse phenotype. BMC Bioinformatics. 2007;8:392.

9. Iles MM, Law MH, Stacey SN, Han J, Fang S, Pfeiffer R, et al. A variant in FTO shows association with melanoma risk not due to BMI. Nat Genet. 2013;45:428-32.e1.

10. Barrett JH, Iles MM, Harland M, Taylor JC, Aitken JF, Andresen PA, et al. Genome-wide association study identifies three new melanoma susceptibility loci. Nat Genet. 2011;43: 1108-13.

11. Macgregor S, Montgomery GW, Liu JZ, Zhao ZZ, Henders AK, Stark M, et al. Genome-wide association study identifies a new melanoma susceptibility locus at 1q21.3. Nat Genet. 2011;43:1114-8.
12. Amos CI, Wang LE, Lee JE, Gershenwald JE, Chen WV, Fang $\mathrm{S}$, et al. Genome-wide association study identifies novel loci predisposing to cutaneous melanoma. Hum Mol Genet. 2011;20:5012-23.

13. Choi M, Scholl UI, Ji W, Liu T, Tikhonova IR, Zumbo P, et al. Genetic diagnosis by whole exome capture and massively parallel DNA sequencing. Proc Natl Acad Sci U S A. 2009;106: 19096-101.

14. Krauthammer M, Kong Y, Bacchiocchi A, Evans P, Pornputtapong $\mathrm{N}, \mathrm{Wu} \mathrm{C}$, et al. Exome sequencing identifies recurrent mutations in NF1 and RASopathy genes in sun-exposed melanomas. Nat Genet. 2015;47:996-1002.

15. Stark MS, Woods SL, Gartside MG, Bonazzi VF, DuttonRegester K, Aoude LG, et al. Frequent somatic mutations in MAP3K5 and MAP3K9 in metastatic melanoma identified by exome sequencing. Nat Genet. 2011;44:165-9.

16. Horn S, Figl A, Rachakonda PS, Fischer C, Sucker A, Gast A, et al. TERT promoter mutations in familial and sporadic melanoma. Science. 2013;339:959-61.

17. Aoude LG, Heitzer E, Johansson P, Gartside M, Wadt K, Pritchard AL, et al. POLE mutations in families predisposed to cutaneous melanoma. Fam Cancer. 2015;14:621-8.

18. Aoude LG, Pritchard AL, Robles-Espinoza CD, Wadt K, Harland $\mathrm{M}$, Choi J, et al. Nonsense mutations in the shelterin complex genes ACD and TERF2IP in familial melanoma. J Natl Cancer Inst. 2015;107:dju408.

19. Wadt KA, Aoude LG, Golmard L, Hansen TV, Sastre-Garau X, Hayward NK, et al. Germline RAD51B truncating mutation in a family with cutaneous melanoma. Fam Cancer. 2015;14: $337-40$.

20. Aoude LG, Wadt K, Bojesen A, Cruger D, Borg A, Trent JM, et al. A BAP1 mutation in a Danish family predisposes to uveal melanoma and other cancers. PLoS One. 2013;8:e72144.

21. Cebulla CM, Binkley EM, Pilarski R, Massengill JB, Rai K, Liebner DA, et al. Analysis of BAP1 germline gene mutation in young uveal melanoma patients. Ophthalmic Genet. 2015; 36:126-31. 